OPEN ACCESS

Edited by:

Kefu Yu,

Guangxi University, China

Reviewed by:

Biao Chen,

Guangxi University, China

Anthony William Larkum,

University of Technology Sydney, Australia

${ }^{*}$ Correspondence:

Ulf Karsten

ulf.karsten@uni-rostock.de

Specialty section: This article was submitted to

Coral Reef Research,

a section of the journal

Frontiers in Marine Science

Received: 22 January 2021

Accepted: 15 March 2021

Published: 01 April 2021

Citation:

Russnak V, Rodriguez-Lanetty M and Karsten U (2021)

Photophysiological Tolerance and Thermal Plasticity of Genetically

Different Symbiodiniaceae

Endosymbiont Species of Cnidaria.

Front. Mar. Sci. 8:657348.

doi: 10.3389/fmars.2021.657348

\section{Photophysiological Tolerance and Thermal Plasticity of Genetically Different Symbiodiniaceae Endosymbiont Species of Cnidaria}

\author{
Vanessa Russnak ${ }^{1}$, Mauricio Rodriguez-Lanetty ${ }^{2}$ and Ulf Karsten ${ }^{1 *}$ \\ ${ }^{1}$ Institute of Biological Sciences, Applied Ecology and Phycology, University of Rostock, Rostock, Germany, ${ }^{2}$ Department \\ of Biological Sciences, Institute of Environment, Florida International University, Miami, FL, United States
}

Coral reefs are endangered by constantly rising water temperature due to global warming. This triggers a breakdown of the nutritional symbiosis between cnidarian hosts and their Symbiodiniaceae symbionts, resulting in the loss of the algal partner. In the Symbiodiniaceae exists a high genetic diversity with broad physiological plasticity within and between species, resulting in large thermal tolerance. While these variations have been studied in individual taxa, comprehensive comparative experimental data on numerous species are still rare. In the present study, the photosynthetic performance and tolerance as function of light and temperature of nine Symbiodiniaceae genetic types of four different clades were determined. The data indicate significant differences in the response patterns. Almost all algal isolates exhibited low to moderate light requirements for photosynthesis without photoinhibition, and a photosynthetic efficiency between 20 and $80 \%$ in the temperature range $20-34^{\circ} \mathrm{C}$, indicating a broad thermal tolerance to temperature fluctuations in tropical regions. The presented data clearly point to a broad photophysiological tolerance and thermal plasticity of genetically different Symbiodiniaceae, which contributes as an important finding to a better understanding of host-symbiont response to an increasing sea surface temperature.

Keywords: irradiance, photosynthesis, respiration, Symbiodiniaceae, temperature, tolerance

\section{INTRODUCTION}

Coral reefs are one of the most important ecosystems in the marine environment, as they are highly diverse and productive ecosystems (Connell, 1978; Moberg and Folke, 1999). The high productivity of coral reef systems is based on a mutualistic symbiosis between unicellular dinoflagellates (Symbiodiniaceae) and different invertebrate reef species, including corals, sea anemones and sponges among many others (Trench, 1993; Coffroth and Santos, 2005; Decelle et al., 2018).

The success of this symbiosis depends on complementary intracellular solute exchange such as nutrients and carbon compounds. The symbionts can provide up to $95 \%$ of photosynthetically fixed organic carbon in the form of glycerol, glucose and alanine to the host (Muscatine and Porter, 1977; Burriesci et al., 2012; Davy et al., 2012). In exchange the host offers protection against environmental stresses (e.g., herbivory) and delivers inorganic nitrogen 
(Davies, 1984; Steen and Muscatine, 1984). Despite their immense ecological importance, coral reefs are diminishing worldwide due to various environmental stressors (HoeghGuldberg et al., 2007; Hughes et al., 2018, 2020). There are several factors, such as low salinity, water pollution, unusually high or low water temperatures or high solar irradiance causing coral bleaching (Van Oppen and Lough, 2018). When, for instance, the local temperature exceeds the upper physiological threshold of the host, the symbiosis collapses and "bleaching" occurs as a result of the loss of algal endosymbionts (Glynn and D'Croz, 1990). This impact has already been observed globally, with an increasing frequency of these "bleaching events" due to more frequent El-Nino events, particularly in recent years (Glynn, 1993; Eakin et al., 2010; Hughes et al., 2017, 2018, 2020). However, the probability of bleaching depends either on the host characteristics (Baird et al., 2009), on the symbiont ecophysiological traits (Rowan, 2004) or on the prevailing environmental conditions (Hoegh-Guldberg, 1999; Anthony et al., 2009). The flexibility of the coral host, in particular, to associate with different photosymbiont strains at the same time could be critical to cope with rapid environmental fluctuations (Baker, 2001; Berkelmans and Van Oppen, 2006; Abrego et al., 2008; Lewis et al., 2019; Qin et al., 2019).

Several studies suggested that the host might be able to acclimate to higher water temperatures by switching to more temperature-tolerant symbiont species or strains from the local environment or by distributing temperature-tolerant symbionts to make them more abundant (Buddemeier and Fautin, 1993; Baker, 2003; Fautin and Buddemeier, 2004; Correa and Baker, 2011; Cunning et al., 2018). Nevertheless, some investigations revealed that altered host-symbiont pairings often return to their original composition when sufficient time elapsed after a bleaching event (Thornhill et al., 2006; Sampayo et al., 2008). For example, this was found in several coral species at the Great Barrier Reef after a bleaching event in 2002. During bleaching, corals harbored the same Symbiodiniaceae as before and after the thermal stress events (Stat et al., 2009). This suggests that not all symbiotic strains are beneficial to the respective host (Stat et al., 2008; Starzak et al., 2014; Gabay et al., 2018) or that the competitive advantage varies with the environment (Thornhill et al., 2006; Jones et al., 2008; LaJeunesse et al., 2009). The Symbiodiniaceae are highly diverse and combine at least seven different genera, which were recently taxonomically revised (LaJeunesse et al., 2018). The six genera are Breviolum, Cladocopium, Durusdinium, Effrenium, Fugacium, and Gerakladium. Members of the Symbiodiniaceae have a different sensitivity to solar radiation and temperature fluctuations. The underlying mechanisms can be explained by biochemical and molecular processes of the photosynthetic machinery (Takahashi et al., 2008). The key pigments peridinin, chlorophyll $a$ and $c 2$ are integrated into the chloroplast membrane as the two major antennas $a$-chlorophyll $c 2$-peridinin protein complex (acpPC) and peridinin-chlorophyll $a$-binding protein (PCP) (Brown et al., 1999; Takahashi et al., 2008; Niedzwiedzki et al., 2014; Hennige et al., 2019).

High irradiances and temperatures are factors contributing to the phenomenon of coral bleaching. High temperature contributes to an increased production of harmful reactive oxygen molecules (ROS), such as hydrogen peroxide $\left(\mathrm{H}_{2} \mathrm{O}_{2}\right)$, singlet oxygen ${ }^{1} \mathrm{O}_{2}$ or superoxide $\mathrm{O}_{2}$. $\mathrm{ROS}$ originate as a metabolic byproduct and are primarily produced by photosystem I and in parts of photosystem II (Szabó et al., 2020). ROS are chemically highly reactive and hence can, for example, mutate DNA, denature proteins and oxidize lipids as well as cell membranes (Takahashi et al., 2008, 2009; Venn et al., 2008; Lesser et al., 2010). As a result of ROS production and the cellular cascade, this can lead to a disruption of communication and interaction between the host and symbiont. ROS production is considered as the key element for the bleaching process (Weis, 2008; Baird et al., 2009; Szabó et al., 2020). Evidence suggests that the ROS leakage varies between species, as well as depending on temperature and salinity (Gegner et al., 2019). Various species of the Symbiodiniaceae acclimate their photosynthetic performance to different light conditions (Iglesias-Prieto and Trench, 1994; Hennige et al., 2009; Suggett et al., 2015). With elevated temperatures, various Symbiodiniaceae did not grow (Lesser, 1996), while other investigations reported the opposite (Sakami, 2000; Karim et al., 2015; Klueter et al., 2017). Karim et al. (2015), for example, that growth and photochemical efficiency of PSII remained unchanged between 25 and $30^{\circ} \mathrm{C}$ in various Symbiodiniaceae genera. At temperatures above $33^{\circ} \mathrm{C}$, however, the thermal tolerance was exceeded. Further reports point to different genotypes of Symbiodiniaceae which are tolerant to specific temperatures and radiation conditions (Robison and Warner, 2006). Consequently, the tolerance width and upper survival temperature varies from species to species and genotype to genotype (Berkelmans and Van Oppen, 2006; Van Oppen et al., 2009). The genetic identity and ecophysiological capability of Symbiodiniaceae species play a major role in acclimation and adaptation to thermal stress. Several studies identified significant differences in heat tolerance both within a single Symbiodiniaceae genus (Díaz-Almeyda et al., 2017; Bayliss et al., 2019) and between genera (Grégoire et al., 2017). In addition, there are several species, such as Durusdinum trenchii (Rowan, 2004; Jones et al., 2008; Bellantuono et al., 2019) and Cladocopium thermophilum (formerly Class C, ITS2"Golf C3") (Hume et al., 2015) which are considered thermotolerant. A genetic subtype of ITS2-D1a (LaJeunesse et al., 2018) within Clade D, gives coral hosts a $1-1.5^{\circ} \mathrm{C}$ increase in thermal tolerance (Rowan, 2004; Berkelmans and Van Oppen, 2006). A culture of Cladocopium C1 in a laboratory selection exhibited better photophysiology and growth at high temperature $\left(31^{\circ} \mathrm{C}\right)$ compared to wild type cells (Chakravarti et al., 2017). However, alternating heat-resistant host-symbiont assemblages are associated with metabolic "costs", since the growth rates of the corals often decrease (Abrego et al., 2008).

The objective of this study was to examine the photosynthetic performance [net primary production], hyperthermal tolerance, acclimation capacity of several genotypes (strains), species, and genera of Symbiodiniaceae using oxygen optodes. Based on previous studies (Rowan, 2004; Jones et al., 2008; Bellantuono et al., 2019), in which Durusdinium trenchii exhibited a pronounced heat tolerance, we hypothesized that $D$. trenchii outperforms the other strains in terms of photosynthetic 
efficiency as no loss of photosynthetic function occurs at higher temperature. A total of nine algal strains belonging to four genera and four species of Symbiodiniaceae were comparatively examined under controlled manipulative conditions: Breviolum minutum (4 strains), Breviolum psygmophilum (2 strains), D. trenchii (one strain), Effrenium voratum (one strain), and Symbiodinium linucheae (one strain).

\section{MATERIALS AND METHODS}

\section{Origin and Maintenance of Symbiodiniaceae}

The photophysiological properties and thermal tolerance of clonal cultures under controlled conditions were investigated in nine different Symbiodiniaceae genetic types from four different clades (A, B, D, and E) (LaJeunesse et al., 2018). These strains originated from the culture collection of the IMaGeS Lab (Dr. Rodriguez-Lanetty; originally started by Dr. Mary Alice Coffroth) of Florida International University Miami. The investigated isolates were isolated from four host species (seven individual hosts) collected in three biogeographic regions [Hawaii (Pacific), Florida (Caribbean), and Panama (Caribbean)]. In addition, Effrenium voratum was utilized as a free-living species from New Zealand waters (West Pacific) (Table 1). These lineages originate from locations with distinct thermal profiles and thus, have likely acquired specific adaptations to their local environments. For example, the strain Breviolum minitum SSB 01 from Hawaii (Pacific) is more temperature sensitive (Dang et al., 2019) compared to heat tolerant Durusdinium trenchii CCMP2556 (Bellantuono et al., 2019) from the Caribbean. All Symbiodiniaceae strains were kept as unialgal cultures under controlled conditions $\left(21^{\circ} \pm 0.6^{\circ} \mathrm{C}\right.$, approx. 35-40 $\mu \mathrm{mol}$ photons $\mathrm{m}^{-2} \mathrm{~s}^{-1}$ at 16:8 $\mathrm{h}$ light dark cycle, provided by Lumilux Cool Daylight L18W/865; OSRAM, Munich, Germany) for at least 6 months in Rostock. The clonal cultures were grown in natural, filtered $(0.2 \mu \mathrm{m}$, Sartorius, Germany) Baltic Sea water (absolute salinity, $14 \mathrm{~S}_{\mathrm{A}}$ ), where the salinity was adjusted to $33 \mathrm{~S}_{\mathrm{A}}$ by adding artificial sea salt (hw Marinemix professional-HW Wiegandt Aquaristik, Krefeld, Germany) and enriched with f/2 medium (Guillard's Medium, type G0154, Sigma Aldrich, Germany). The stock culture media were refreshed monthly. The medium was refreshed
3-4 days prior each experiment to ensure always growth in the log phase.

\section{Genetic Identity}

Genetic identity of the Symbiodiniaceae cultures was confirmed and evaluated by amplification and sequencing of the hypervariable region of domain $\mathrm{V}$ of the chloroplast 23S ribosomal DNA gene (cpr23S), which is considered as a Symbiodinium-specific molecular marker (GranadosCifuentes et al., 2015; Bonthond et al., 2018). This region was identified with the forward primer 23S_F-Forward_Overhang (TCGTCGGCAGCGTCAGATGTGTATAAGAGACAGAATAA CGACCTGCATGAAAC, Invitrogen) and reverse primer 23S_RReverse_Overhang (GTCTCGTGGCTCGGAGATGTGTATA AGAGACAGGCCTGTTATCCGTAGAGTAGC, Invitrogen). The PCR profile was as follows: initial denaturation for $2 \mathrm{~min}$ at $95^{\circ} \mathrm{C}, 35$ cycles at $95^{\circ} \mathrm{C}$ for $35 \mathrm{~s}, 35$ cycles $55^{\circ} \mathrm{C}$ for $30 \mathrm{~s}, 35$ cycles $72^{\circ} \mathrm{C}$ for $60 \mathrm{~s}$, followed by a final extension of $5 \mathrm{~min}$ at $72^{\circ} \mathrm{C}$. The PCRs contained 1X GoTaq GreenMaster Mix (Promega), 0.625 $\mu l$ per primer and nuclease-free water in a final volume of $25 \mu \mathrm{l}$. For each sample $1 \mu \mathrm{l}$ of template DNA was used. Purified PCR product were sent to Eurofins for sequencing using the Sanger-O Primer. Received dinoflagellates sequences were adjusted and aligned with the program SnapGene Viewer. Sequences were BLASTn search against the GenBank from National Center for Biotechnology Information (NCBI) for species identification.

\section{Photosynthesis and Respiration Measurements}

The photosynthesis irradiance curves (PI curve) reflect the measured relationship of oxygen production per chlorophyll $a$ as function of increasing photon fluence densities (PFD). For this purpose, the PI curves were generated in four separate watersurrounded oxygen electrode chambers (Hansatech Instruments, King's Lynn, United Kingdom), each filled on top of a magnetic stirrer (Hansatech Instruments, King's Lynn, United Kingdom). The chambers were connected to a water supply (K10, Thermo Haake, Karlsruhe, Germany) and a thermostat (DC10, Thermo Haake, Karlsruhe, Germany) to keep the temperature constant $\left( \pm 0.1^{\circ} \mathrm{C}\right)$. LEDs (LUXEON Rebel1 LXML-PWN1-0100, neutral white, Phillips, Amsterdam) were used as light sources, which were implemented in the PI-Box. To reduce the photon flux densities (PFD), neutral density filters were placed between the

TABLE 1 | Culture and taxonomic assignment of the investigated Symbiodiniaceae genotypes, along with information on origin, lifestyle, and isolator.

\begin{tabular}{|c|c|c|c|c|c|c|c|}
\hline Culture & Symbiodiniaceae type & Host & origin & Lifestyle & Isolated by & $18 S$ rDNA & cp-type \\
\hline Mf $1.05 \mathrm{~b}$ & Breviolum minutum & Orbicella faveolata & Caribbean & Symbiotic & M.A. Coffroth & $\mathrm{B}$ & B184 \\
\hline SSB 01 & Breviolum minutum & Aiptasia pulchella & Pacific & Symbiotic & Xiang & $\mathrm{B}$ & \\
\hline RT-002 & Breviolum minutum & Aiptasia pallida & Caribbean & Symbiotic & R.K. Trench & $\mathrm{B}$ & \\
\hline MAC 703 & Breviolum minutum & Plexaura kuna & Caribbean & Symbiotic & M.A. Coffroth & $\mathrm{B}$ & B211 \\
\hline CCMP 421 & Effrenium voratum & - & W. Pacific & Free-living & Bigelow & $E$ & E202 \\
\hline MAC HIAP & Breviolum psygmophilum & Aiptasia pulchella & Pacific & Symbiotic & R.A. Kinzie & $\mathrm{B}$ & B224 \\
\hline 1046 & Breviolum psygmophilum & - & & Symbiotic & & $\mathrm{B}$ & \\
\hline CCMP 2556 & Durusdinium trenchii & Orbicella faveolata & Caribbean & Symbiotic & M.A. Coffroth & $D$ & D206 \\
\hline SSA 01 & Symbiodinium linucheae & Aiptasia pallida & Caribbean & Symbiotic & T. Bieri & $A$ & \\
\hline
\end{tabular}


LEDs and the cuvette to generate different PFDs $(0-1,400 \mu \mathrm{mol}$ photons $\mathrm{m}^{-2} \mathrm{~s}^{-1}$ ). Each cuvette was equipped with an integrated oxygen immersion probe (optode) (PreSens Precision Sensing $\mathrm{GmbH}$, Regensburg) and connected via a fiber optic to an oxygen transmitter (Oxy 4-Mini, PreSens Precision Sensing GmbH, Regensburg). For each cuvette, the oxygen concentrations were displayed and recorded with the computer program OXY4v2_30 (PreSens Precision Sensing GmbH, Regensburg) and later calculated based on the chlorophyll $a$ content. To calibrate the oxygen dip probes, each cuvette was treated at 0 and $100 \%$ oxygen saturation at $20^{\circ} \mathrm{C}$. Oxygen saturation at $100 \%$ was done by aeration of the culture media for $15 \mathrm{~min}$. Sodium dithionite $\left(\mathrm{Na}_{2} \mathrm{~S}_{2} \mathrm{O}_{4}\right)$ was used to achieve oxygen free media.

In each measurement, four replicates of $3 \mathrm{ml}$ pre-incubated log-phase suspension of Symbiodiniaceae were loaded into the cuvette. All replicates were enriched with sodium bicarbonate $\left(\mathrm{NaHCO}_{3}, 2 \mathrm{mM}\right.$ final concentration) before the measurements to ensure sufficient carbon supply. Each PI measurement started with a $30 \mathrm{~min}$ respiration phase in darkness, followed by an always 10 min photosynthesis phase at each of 10 different light level, at a constant temperature of $20^{\circ} \mathrm{C}$. After each PI curve measurement, the algal suspension was filtered from each cuvette onto an individual Whatman GF/6 glass fiber filter ( $\varnothing 25 \mathrm{~mm}$ ) for chlorophyll $a$ determination. Chlorophyll $a$ was extracted with $3 \mathrm{ml} \mathrm{96 \%} \mathrm{ethanol} \mathrm{(v/v),} \mathrm{thoroughly} \mathrm{vortexed} \mathrm{and} \mathrm{incubated} \mathrm{in}$ the dark for $24 \mathrm{~h}$ at $4^{\circ} \mathrm{C}$. Afterward the extracts were centrifuged at 5,000 rpm for $10 \mathrm{~min}$ (Heraeus Megafuge, Hanau, Germany) to reduce turbidity. The extinction of the supernatants were measured at 665 and $750 \mathrm{~nm}$ in a spectrophotometer (Shimadzu UV-2401 PC, Kyoto, Japan). The concentration of chlorophyll $a$ was calculated according to a protocol of the Baltic Marine Environment Protection Commission (1988) (Helcom, 1988).

To generate the PI curve, the chlorophyll $a$ content and the measured data were fitted using the mathematical photosynthesis model of Platt et al. (1980). Several photosynthesis parameters were estimated from the least square's regression curves, which were adjusted to the measured values using the solver function of MS Office excel 2013. Based on these curves, the maximum rate of net primary production $\left(\mathrm{NPP}_{\max }\right)$, respiration $(\mathrm{R})$, light utilization coefficient $(\alpha)$, photoinhibition coefficient $(B)$, light saturation point $\left(\mathrm{I}_{\mathrm{k}}\right)$ and light compensation point $\left(\mathrm{I}_{\mathrm{c}}\right)$ were calculated.

\section{Temperature Dependent Photosynthesis and Respiration}

To investigate the temperature requirements of photosynthesis and respiration, two different temperature treatments were applied. The first and broader experiment aimed to define the upper and lower temperature tolerance along with the optimum for each strain in the temperature range from $10^{\circ} \mathrm{C}$ up to $40^{\circ} \mathrm{C}$ and down to $10^{\circ} \mathrm{C}$ in $5^{\circ} \mathrm{C}$ increments.

The second temperature experiment was carried out based on the previously gained data with smaller temperature range and steps to precisely identify the upper temperature limits for both photosynthesis and respiration. The responses between the temperatures $20^{\circ} \mathrm{C}$ up to $34^{\circ} \mathrm{C}$ in $2^{\circ} \mathrm{C}$ steps were measured. Both experiments were performed using the oxygen-optode system described above with four replicates of $3 \mathrm{ml}$ pre-incubated log-phase suspension of Symbiodiniaceae at the same time. Each sample was incubated in the dark for $20 \mathrm{~min}$ at each experimental temperature, starting at the respective starting temperature $\left(10^{\circ} \mathrm{C} / 20^{\circ} \mathrm{C}\right)$, before respiration was monitored for an additional $10 \mathrm{~min}$. This was followed by the photosynthesis phase for an additional $10 \mathrm{~min}$ at an exposure of $\sim 340 \mu \mathrm{mol}$ photons $\mathrm{m}^{-2} \mathrm{~s}^{-1}$. This light level was held constant for all photosynthesis measurements. After determining photosynthetic oxygen evolution, the temperature was increased by $5^{\circ} \mathrm{C} / 2^{\circ} \mathrm{C}$ and a new incubation period was started after reaching the new temperature in the thermostat chamber. The $\mathrm{O}_{2}$ consumption and production per unit time were related to the concentration of total Chl $a$ per sample as described above.

\section{Statistics}

All values shown represent mean values and standard deviation ( $n=4)$, unless otherwise stated. For statistical analysis, IBM's SPSS Statistics 25 computer program was applied. Significance levels were calculated using one-way ANOVAs with post hoc Tukey tests to show significant differences between the different temperature levels. For the assumptions, normality was previously tested with the Shapiro-Wilk test and for homogeneity of variances, the Levene's test $(p>0.05)$ was applied. For violation of assumptions, if Levene's test was significant, WelchANOVA and Games-Howell post hoc test were performed instead of a one-way ANOVA. For all ANOVAS, "photosynthesis" and "respiration" were used as independent variables (= levels).

\section{RESULTS}

\section{Photosynthesis and Respiration Measurements}

Photosynthetic oxygen production in all Symbiodiniaceae cultures at $20^{\circ} \mathrm{C}$ showed a similar PI curve shape with increasing $\mathrm{PFD}$, followed by rarely perceived photoinhibition (Figure 1). The average respiration rate at $20^{\circ} \mathrm{C}$ ranged from $-38.33 \mu \mathrm{mol}$ $\mathrm{O}_{2} \mathrm{mg}^{-1} \mathrm{Chl} a \mathrm{~h}^{-1}$ in strain SSB 01 to $-127.40 \mu \mathrm{mol} \mathrm{O} \mathrm{mg}^{-1}$ Chl $a \mathrm{~h}^{-1}$ in strain SSA 01, while the maximum photosynthesis rate $\mathrm{NNP}_{\text {max }}$ in the light saturated range was between $47.21 \mu \mathrm{mol}$ $\mathrm{O}_{2} \mathrm{mg}^{-1} \mathrm{Chl} a \mathrm{~h}^{-1}$ in strain SSA 01 and $233.45 \mu \mathrm{mol} \mathrm{O} \mathrm{mg}^{-1}$ Chl $a \mathrm{~h}^{-1}$ in strain 1,046 (Figure 1). Even under the highest tested photon fluence density $\left(1,400 \mu \mathrm{mol}\right.$ photons $\left.\mathrm{m}^{-2} \mathrm{~s}^{-1}\right)$, only in SSB 01 small photoinhibition could be demonstrated (Figure 1B). The Symbiodiniaceae genotypes showed an alpha value (photosyntethic efficiency) between 2.66 and $6.09 \mu \mathrm{mol}$ $\mathrm{O}_{2} \mathrm{mg}^{-1} \mathrm{Chl} a \mathrm{~h}^{-1}$ ( $\mu \mathrm{mol}$ photons $\mathrm{m}^{-2} \mathrm{~s}^{-1}$ ) ${ }^{-1}$, whereas SSA 01 exhibited a very high alpha value with $39 \mu \mathrm{mol} \mathrm{O} \mathrm{mg}^{-1}$ Chl $a \mathrm{~h}^{-1}$ ( $\mu \mathrm{mol}$ photons $\left.\mathrm{m}^{-2} \mathrm{~s}^{-1}\right)^{-1}$. The values of the light saturation point $\left(\mathrm{I}_{\mathrm{k}}\right)$ ranged from $4.48 \mu \mathrm{mol}$ photons $\mathrm{m}^{-2} \mathrm{~s}^{-1}$ in strain SSA 01-110.26 $\mu \mathrm{mol}$ photons $\mathrm{m}^{-2} \mathrm{~s}^{-1}$ in strain MAC HIAp, and those of the light compensation point $\left(\mathrm{I}_{\mathrm{c}}\right)$ between 5.84 (strain SSA 01) and $35.73 \mu \mathrm{mol}$ photons $\mathrm{m}^{-2} \mathrm{~s}^{-1}$ (strain 1,046) (Figure 1 and Table 2). All these values indicate low to moderate light requirements for photosynthesis at $20^{\circ} \mathrm{C}$, with the 


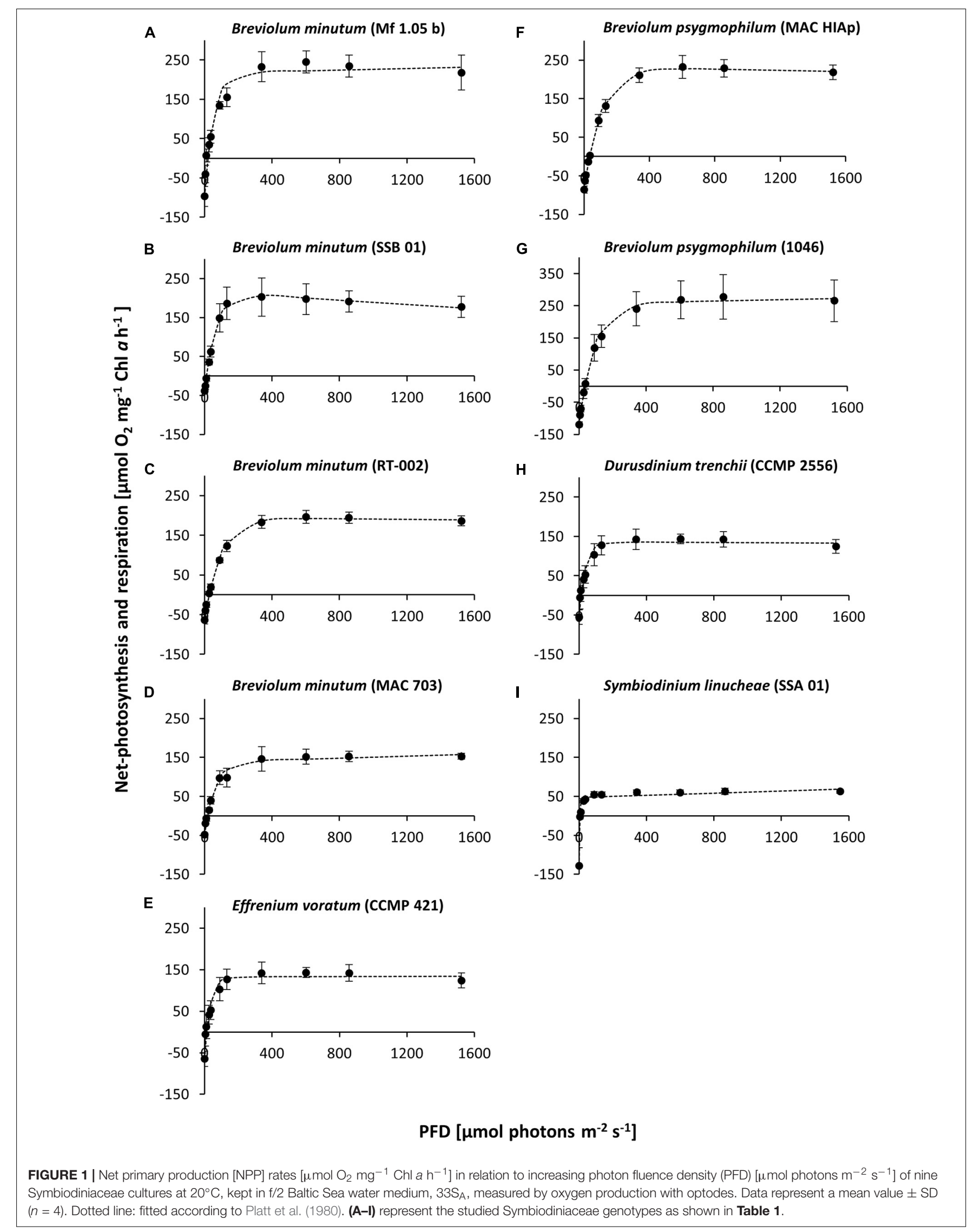


TABLE 2 | Parameter of respective Pl-curves (Figures 1A-I) of nine Symbiodiniaceae cultures $\left(n=4\right.$, mean value \pm SD) at $20^{\circ} \mathrm{C}$ kept in a f/2 Baltic Sea water medium, $33 S_{A}$.

\begin{tabular}{|c|c|c|c|c|c|c|}
\hline Strains & $\begin{array}{c}\text { NPP } \max \left[\mu \mathrm{mol} \mathrm{O}_{2} \mathrm{mg}^{-1}\right. \\
\mathrm{Chl} \mathrm{ah^{-1 } ]}\end{array}$ & $\begin{array}{c}\text { Respiration }\left[\mu \mathrm{mol} \mathrm{O} \mathrm{O}_{2}\right. \\
\left.\mathrm{mg}^{-1} \mathrm{Chl} \mathrm{a} \mathrm{h}^{-1}\right]\end{array}$ & $\begin{array}{c}\alpha\left[\mu \mathrm{mol} \mathrm{O}_{2} \mathrm{mg}^{-1} \mathrm{Chl} \mathrm{a}\right. \\
\mathrm{h}^{-1}[\mu \mathrm{mol} \text { photons } \\
\left.\left.\mathrm{m}^{-2} \mathrm{~s}^{-1}\right]^{-1}\right]\end{array}$ & $\begin{array}{c}\beta\left[\mu \mathrm{mol} \mathrm{O} \mathrm{mg}^{-1} \mathrm{Chl} \mathrm{a}\right. \\
\mathrm{h}^{-1}[\mu \mathrm{mol} \text { photons } \\
\left.\left.\mathrm{m}^{-2} \mathrm{~s}^{-1}\right]^{-1}\right]\end{array}$ & $\begin{array}{c}\mathrm{I}_{\mathrm{k}}[\mu \mathrm{mol} \text { photons } \\
\left.\mathrm{m}^{-2} \mathrm{~s}^{-1}\right]\end{array}$ & $\begin{array}{c}\mathrm{I}_{\mathrm{c}}[\mu \mathrm{mol} \text { photons } \\
\left.\mathrm{m}^{-2} \mathrm{~s}^{-1}\right]\end{array}$ \\
\hline Mf 1.05b & $212.56 \pm 46.98$ & $-97.17 \pm 25.78$ & $5.73 \pm 1.72$ & $-0.01 \pm 0.04$ & $54.08 \pm 16.99$ & $20.36 \pm 3.12$ \\
\hline SSB01 & $218.28 \pm 57.05$ & $-38.33 \pm 5.90$ & $3.73 \pm 0.45$ & $0.03 \pm 0.03$ & $68.79 \pm 11.69$ & $11.02 \pm 2.30$ \\
\hline RT-002 & $194.92 \pm 23.41$ & $-63.36 \pm 9.93$ & $2.66 \pm 0.24$ & $0.00 \pm 0.01$ & $97.06 \pm 9.94$ & $27.26 \pm 3.67$ \\
\hline MAC 703 & $133.34 \pm 38.73$ & $-47.56 \pm 4.39$ & $3.01 \pm 0.26$ & $-0.01 \pm 0.02$ & $60.05 \pm 11.41$ & $18.34 \pm 3.10$ \\
\hline CCMP 421 & $132.49 \pm 21.37$ & $-64.51 \pm 18.07$ & $6.09 \pm 1.15$ & $0.00 \pm 0.01$ & $32.35 \pm 5.06$ & $12.83 \pm 5.47$ \\
\hline MAC HIAp & $233.45 \pm 29.59$ & $-85.69 \pm 9.33$ & $2.89 \pm 0.48$ & $0.01 \pm 0.01$ & $110.26 \pm 8.78$ & $34.34 \pm 3.21$ \\
\hline 1046 & $249.35 \pm 57.35$ & $-119.19 \pm 5.47$ & $4.03 \pm 1.05$ & $-0.01 \pm 0.01$ & $91.53 \pm 17.85$ & $35.73 \pm 5.08$ \\
\hline CCMP 2556 & $136.30 \pm 16.26$ & $-55.14 \pm 18.22$ & $5.16 \pm 2.64$ & $0.00 \pm 0.01$ & $37.07 \pm 17.85$ & $12.59 \pm 5.08$ \\
\hline SSA01 & $47.21 \pm 7.93$ & $-127.40 \pm 19.36$ & $39.00 \pm 19.38$ & $-0.01 \pm 0.01$ & $4.48 \pm 1.49$ & $5.84 \pm 1.03$ \\
\hline
\end{tabular}

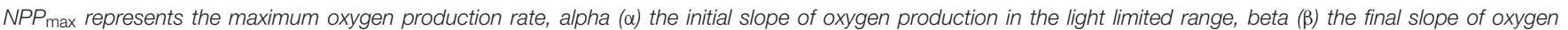
production in the light saturated range (photoinhibition), $I_{\mathrm{c}}$ the light compensation point where respiration and photosynthesis are equal, $I_{\mathrm{k}}$ the light saturation point.

exception of Symbiodinium linucheae which revealed a strong increase with a rather low maximum oxygen production rate $\left(\mathrm{NNP}_{\max }\right)$ (Figure 1I).

Overall, the data document genotype-specific similarities and differences between the nine Symbiodiniaceae isolates. While, for example, similar PI curves concerning the $\mathrm{NNP}_{\max }$ values were recorded for members of the different genera B. minutum, D. trenchii, and E. voratum (MAC 703, CCMP 2556, and CCMP 421 ), the PI curves within the genus Breviolum varied widely. Both isolates of B. psygmophilum showed a remarkably similar $\mathrm{NNP}_{\text {max }}$, as well as light compensation and light saturation point. On the other hand, all Breviolum minutum strains exhibited a wide range of $\mathrm{NNP}_{\max }$ values. In addition, SSB 01 showed a slight photoinhibition $(\beta)$. Furthermore, S. linucheae (SSA 01) had the lowest $\mathrm{NNP}_{\max }$, while B. psygmophilum (1046) showed the highest $\mathrm{NNP}_{\max }$ (Figures 1I,G).

\section{Temperature Dependent Photosynthesis and Respiration}

The effects of temperature on the production of photosynthetic oxygen and respiratory oxygen consumption in Symbiodiniaceae cultures displayed strong differences within and between the strains with an increasing temperature gradient.

A broad temperature experiment (Figure 2) was conducted from $10^{\circ} \mathrm{C}$ up to $40^{\circ} \mathrm{C}$, with a recovery phase decreasing the temperature back to $10^{\circ} \mathrm{C}$. All isolates showed a weak photosynthetic and respiratory rate at $10^{\circ} \mathrm{C}$. Increasing temperature stimulated photosynthesis and respiration to a species-specific maximum, followed by a decrease under the highest temperature conditions. While optimal photosynthesis was measured between 20 and $30^{\circ} \mathrm{C}$ in all investigated strains, the highest respiration occurred between 30 and $40^{\circ} \mathrm{C}$ (Figure 2). Furthermore, after a complete inhibition of photosynthesis at $40^{\circ} \mathrm{C}$, no recovery was observed when the temperature was subsequently lowered, indicating a damage to the photosynthesis apparatus. This was illustrated by a two-color triangle in the graph (A-I). All cultures showed still respiration in the dark at $40^{\circ} \mathrm{C}$ (Figure 2). Subsequently, four (Figures 2B,E,I,H) out of nine cultures exhibited a complete inhibition of photosynthesis along with high respiration rates from 30 to $35^{\circ} \mathrm{C}$. The remaining five strains (Figures $\mathbf{2 A}, \mathbf{C}, \mathbf{D}, \mathbf{F}, \mathbf{G}$ ) showed still a partly functioning photosynthesis at $35^{\circ} \mathrm{C}$. Both strains of B. psygmophilum reached the highest values in photosynthetic oxygen evolution (MAC HIAp: $264.76 \mu \mathrm{mol} \mathrm{O}_{2} \mathrm{mg}^{-1}$ Chl $a \mathrm{~h}^{-1}$; strain 1046: $201.70 \mu \mathrm{mol} \mathrm{O} \mathrm{mg}^{-1} \mathrm{Chl} a \mathrm{~h}^{-1}$ ) (F, G). In contrast, B. minutum (SSB 01) showed the lowest maximum value at $20^{\circ} \mathrm{C}$ with $\sim 59.98 \mu \mathrm{mol} \mathrm{O} \mathrm{mg}^{-1} \mathrm{Chl} a$ $\mathrm{h}^{-1}$ (B). Therefore, SSB 01 was the only strain with maximum photosynthetic oxygen evolution at $20-25^{\circ} \mathrm{C}$, while all other isolates had their maxima between 25 and $30^{\circ} \mathrm{C}$ (Figure 2). At $35^{\circ} \mathrm{C}$ photosynthesis of E. voratum was completely inhibited. In contrast, the other eight cultures showed only slightly decreased or constant respiration during the light phase at $35^{\circ} \mathrm{C}$ (Figures 2A-I).

A second experiment was carried out to identify more precisely the temperature requirements of photosynthesis and respiration in the critical range between 20 and $34^{\circ} \mathrm{C}$ (Figures 3A-I). The data confirmed in principle the previous experiment. Eight out of nine strains showed photosynthesis and respiration between 20 and $34^{\circ} \mathrm{C}$, although at the highest temperature some inhibition in oxygen production could be observed. B. minutum (SSB 01) was the only exception as photosynthesis $>28^{\circ} \mathrm{C}$ was fully inhibited (Figure 3B). To determine the optimum temperature for photosynthesis, we applied the widely used model of Blanchard et al. (1996) (Figure 4 and Table 3). It shows the species-specific tolerance range of temperature for photosynthesis and respiration in both temperature experiments. For all cultures percentiles of $<20 \%$, $20-80 \%$, and $>80 \%$ were determined. In the broad temperature approach, all Symbiodiniaceae exhibited a wide temperature tolerance, with almost all values above the $20 \%$ percentile. At the lowest tested temperature $\left(10^{\circ} \mathrm{C}\right)$, four isolates ( $\mathrm{Mf} 1.05 \mathrm{~b}$, MAC 703, MAC HIAp, CCMP 2556) showed efficiency below $20 \%$. All other strains had efficiency between 20 and $80 \%$. Four isolates (Mf 1.05 b, 1046, SSA 01, CCMP 421) exhibited the largest temperature range in the upper percentile by covering three temperature levels from 20 to $30^{\circ} \mathrm{C}$. In comparison, 


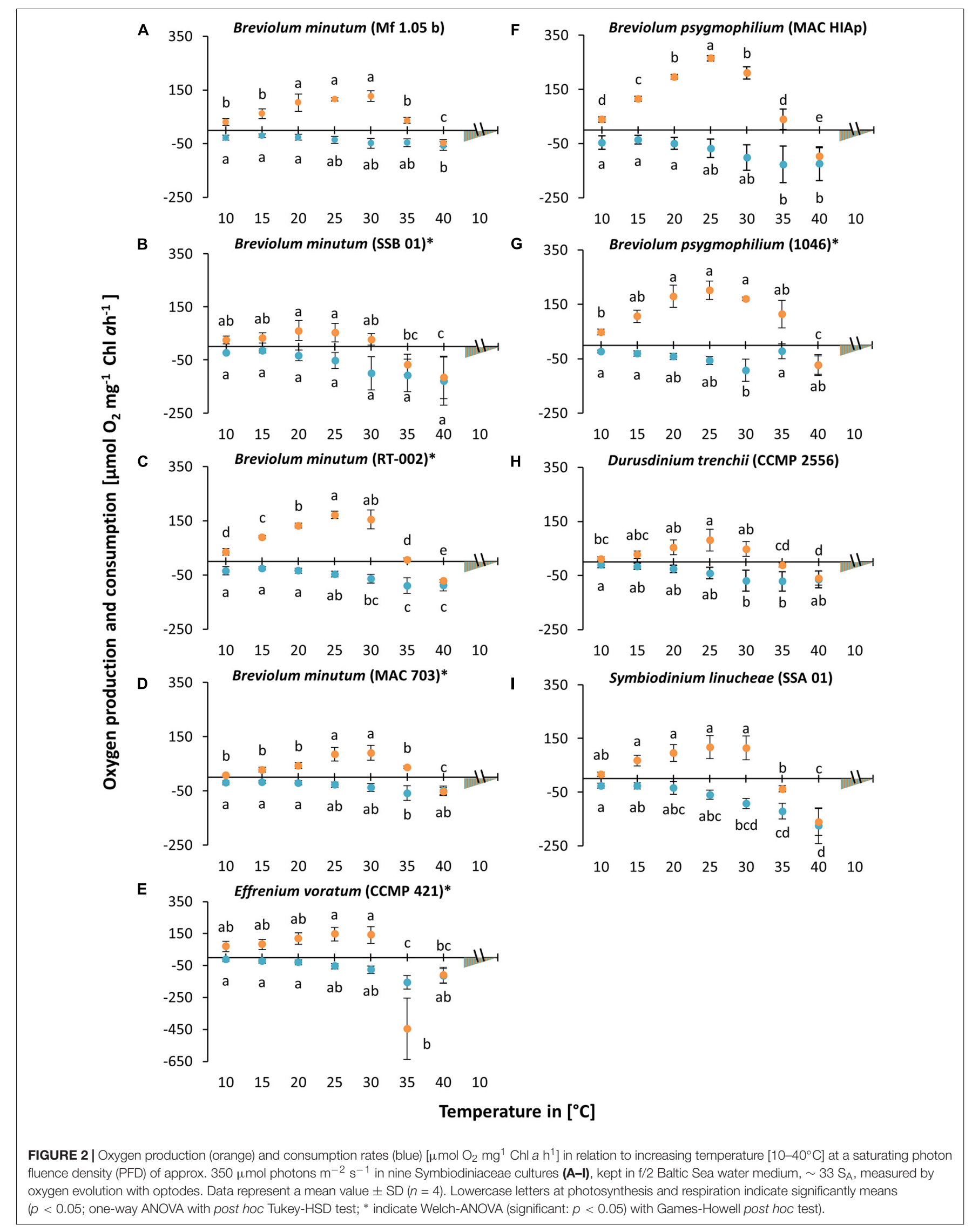




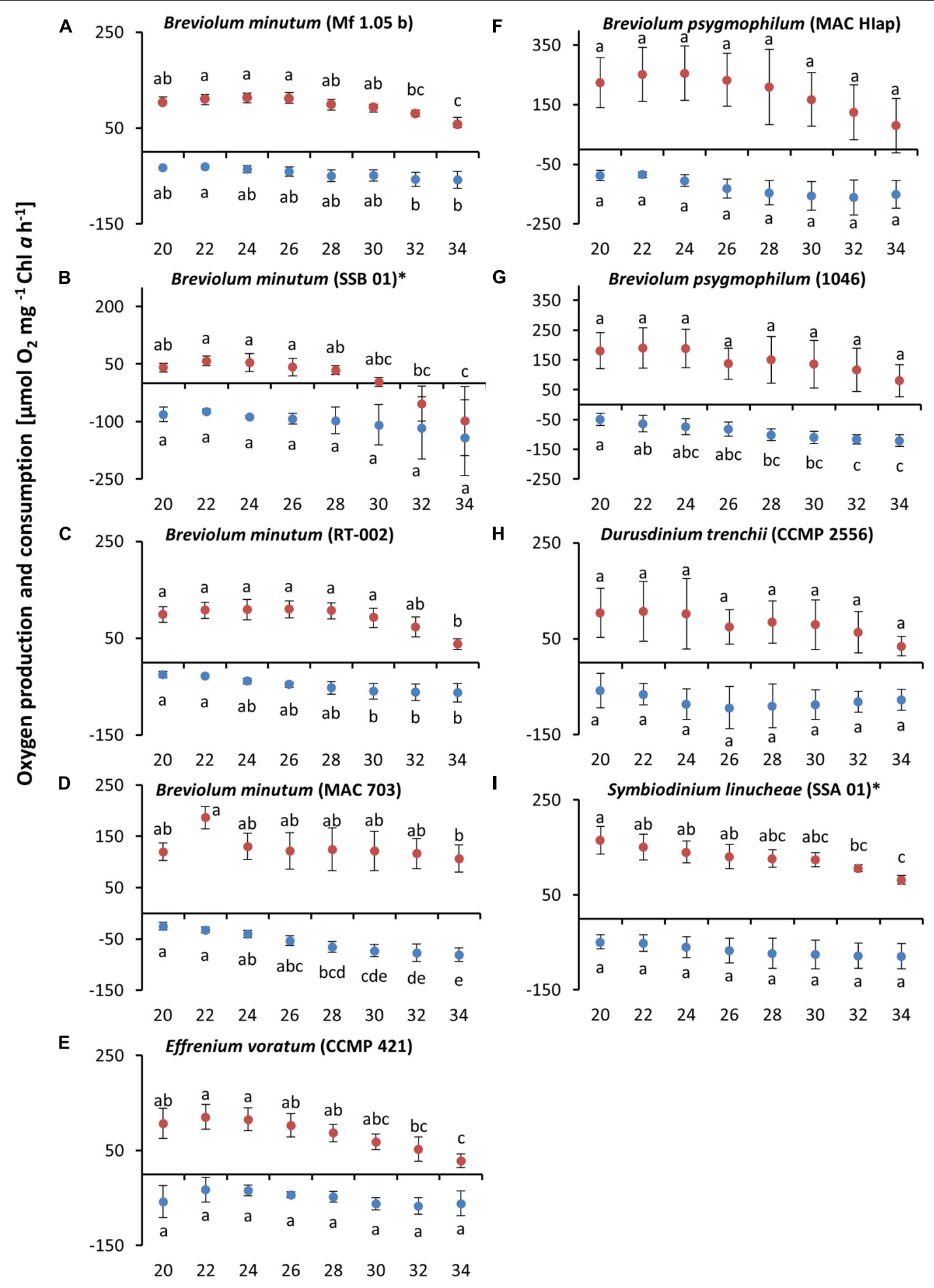

Temperature in $\left[{ }^{\circ} \mathrm{C}\right]$

FIGURE 3 | Oxygen production (red) and consumption rates (dark blue) $\left[\mu \mathrm{mol} \mathrm{O}_{2} \mathrm{mg}^{-1} \mathrm{Chl} \mathrm{a} \mathrm{h}^{-1}\right]$ in relation to increasing temperature [20-34 $\left.{ }^{\circ} \mathrm{C}\right]$ at a saturating photon fluence density (PFD) of approx. $350 \mu \mathrm{mol}$ photons $\mathrm{m}^{-2} \mathrm{~s}^{-1}$ in nine Symbiodiniaceae cultures (A-I), kept in $\mathrm{f} / 2$ Baltic Sea water medium, $\sim 33 \mathrm{~S}_{\mathrm{A}}$, measured by oxygen evolution with optodes. Data represent a mean value $\pm \mathrm{SD}(n=4)$. Lowercase letters at photosynthesis and respiration indicate significantly means ( $p<0.05$; one-way ANOVA with post hoc Tukey-HSD test; * indicate Welch-ANOVA (significant: $p<0.05$ ) with Games-Howell post hoc test). 


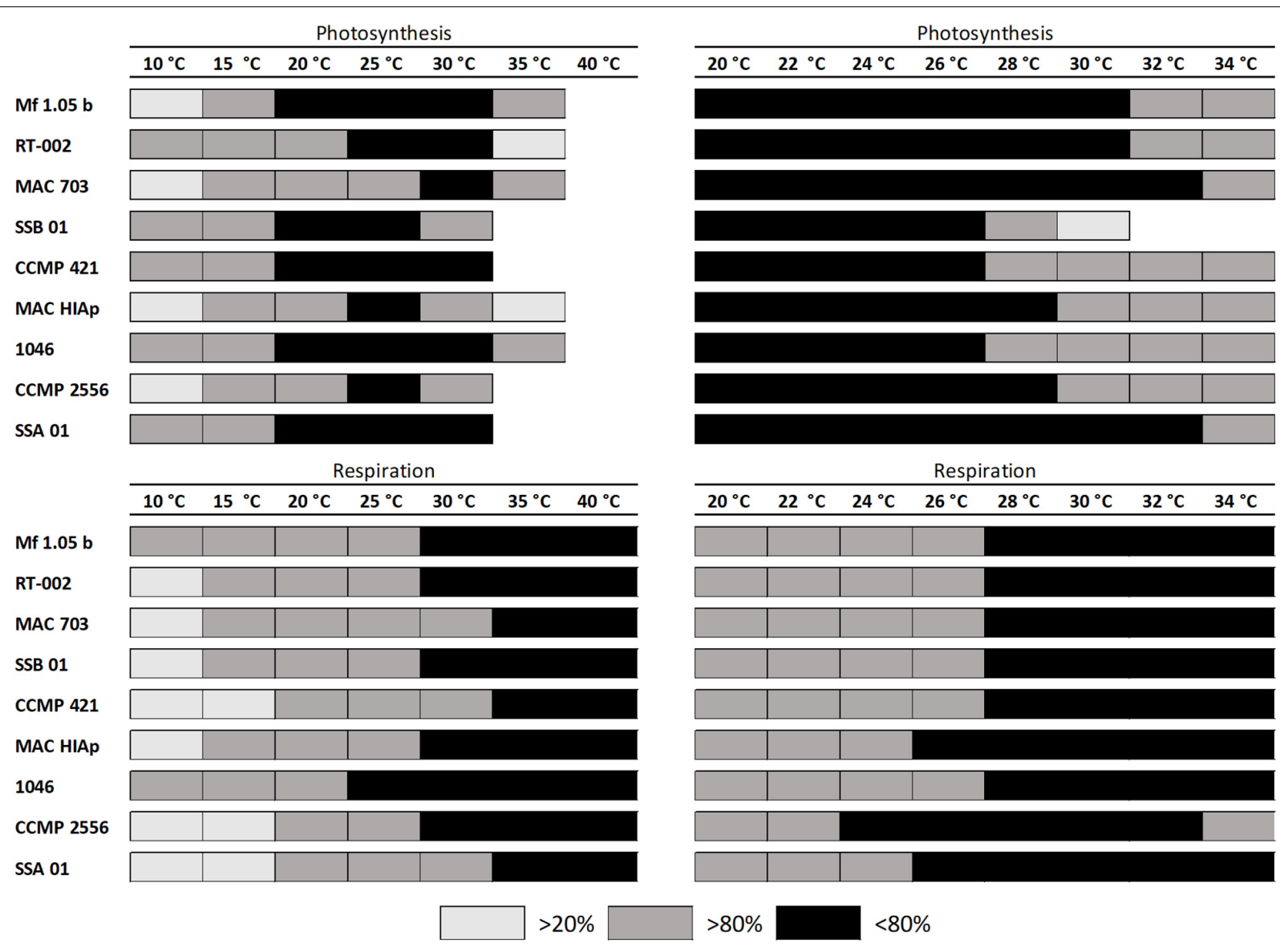

FIGURE 4 | Influence of temperature on photosynthetic oxygen production and respiratory oxygen consumption of nine tested Symbiodiniaceae strains using the fit of Blanchard et al. (1996). The black box represents area of highest photosynthesis more than $>80 \%$ percentile, dark gray symbols within 20 and $80 \%$ percentile light gray symbols $<20 \%$ percentile and white spaces no photosynthesis or respiratory signal. The data represent mean values $(n=4)$.

several strains showed a small range for photosynthetic efficiency, MAC HIAp and CCMP 2556 at $25^{\circ} \mathrm{C}$ and MAC 703 at $30^{\circ} \mathrm{C}$. Photosynthesis was not detectable at $35^{\circ} \mathrm{C}$ in four of nine strains (SSB 01, CCMP 2556, SSA 01, CCMP 421). At $35^{\circ} \mathrm{C}$ the other cultures showed different efficiencies, for RT-002 and MAC HIAp the efficiency ranged below $20 \%$, for the remaining isolates the efficiency reached $20-80 \%$. The highest respiration values were measured between 30 and $40^{\circ} \mathrm{C}$. The respiration increased above the $80 \%$ for different strains at different temperatures (Figure 4 and Table 3).

The critical temperature levels from the experiments were analyzed in more detail and all cultures without a "cold stress" had a photosynthetic efficiency in the upper percentile of over $80 \%$ from $20^{\circ} \mathrm{C}$ up to $26^{\circ} \mathrm{C}$. MAC 703 and SSA 01 exhibited largest temperature tolerance as reflected in the upper percentile $>80 \%$ up to $32^{\circ} \mathrm{C}$. In contrast, SSB 01, 1046, and CCMP 421 showed highest photosynthetic efficiency in the upper percentile up to the $26^{\circ} \mathrm{C}$ range. The different strains tested showed an increased respiration at $28^{\circ} \mathrm{C}$ with more than $>80 \%$, while CCMP 2556, MAC HIAp, and SSA 01 exhibited lower temperature values ( 24 and $26^{\circ} \mathrm{C}$, respectively) (Figure 4 and Table 3 ). The results indicate that all investigated strains have a broad temperature tolerance for photosynthesis and respiration.

\section{DISCUSSION}

The susceptibility of corals is influenced by a variety of abiotic factors such as increased light and temperature conditions, and the physiological and genetic diversity of the endosymbionts strongly contribute to different response patterns of the host (Berkelmans and Van Oppen, 2006; Robison and Warner, 2006; Baird et al., 2009). In the present study the experiments focused on the physiological tolerance and plasticity of genetically different Symbiodiniaceae strains in response to elevated temperatures for a better understanding of their photosynthetic traits as a function of light and temperature.

The Symbiodiniaceae used were grown as unialgal cultures under identical and controlled conditions for at least 1 year, which might explain relatively similar alpha, $I_{c}$ and $I_{k}$ values derived from the respective PI curves. Symbiodiniaceae species acclimate their photosynthetic performance to various light levels (Iglesias-Prieto and 


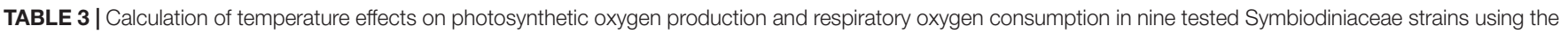
fit of Blanchard et al. (1996).

\begin{tabular}{|c|c|c|c|c|c|c|c|}
\hline & \multirow[b]{3}{*}{ Strains } & \multicolumn{3}{|c|}{ Photosynthesis } & \multicolumn{3}{|c|}{ Respiration } \\
\hline & & \multicolumn{3}{|c|}{ Temperature $\left[{ }^{\circ} \mathbf{C}\right]$} & \multicolumn{3}{|c|}{ Temperature $\left[{ }^{\circ} \mathbf{C}\right]$} \\
\hline & & $100 \%$ & $>80 \%$ & $>20 \%$ & $100 \%$ & $>80 \%$ & $>20 \%$ \\
\hline \multirow[t]{9}{*}{$10-40^{\circ} \mathrm{C}$} & Mf 1.05 b & 24.7 & $19.4-30.1$ & $10.4-35.4$ & 38.7 & 27.0-(49.9) & (5.9)-(67.9) \\
\hline & RT-002 & 26.4 & $20.6-31.2$ & (8.3)-37.3 & 40 & $30.0-(49.0)$ & 10.9-(61.9) \\
\hline & MAC 703 & 28.5 & $24.0-32.1$ & $14.1-36.3$ & 38.9 & $30.5-(47.9)$ & $13.1-(62.2)$ \\
\hline & SSB 01 & 22.4 & $17.7-26.8$ & $(6.2)-32.4$ & 36.4 & 27.5-(44.9) & $12-(58.6)$ \\
\hline & CCMP 421 & 28.2 & $19.0-34.9$ & $(4.6)-(41.6)$ & 38.9 & $32.7-(44.9)$ & $21.7-(54.5)$ \\
\hline & MAC HIAp & 25.9 & $21.0-29.8$ & $10.7-34.5$ & 38.2 & $29.5-(46.0)$ & $13.2-(57.7)$ \\
\hline & 1046 & 25.1 & $19.0-31.1$ & $(8.9)-41.2$ & 32.9 & $22.9-(42.8)$ & (6)-(59.4) \\
\hline & CCMP 2556 & 24.2 & $20.2-28.2$ & $13.5-35.0$ & 35.4 & 28.8-(40.9) & 15-(47.8) \\
\hline & SSA 01 & 27.2 & 19.9-33.8 & (5.8)-(43.5) & 40 & $33.2-(46.5)$ & 21.2-(56.9) \\
\hline \multirow[t]{9}{*}{$20-34^{\circ} \mathrm{C}$} & Mf $1.05 \mathrm{~b}$ & 24 & $17.9-30.1$ & $(7.4)-(40.0)$ & 34 & 26.6-(41) & $(13.1)-(51.9)$ \\
\hline & RT-002 & 25.2 & $16.9-30.6$ & (4.9)-(36.7) & 33 & 27.2-(37.9) & $(15.3)-(42.2)$ \\
\hline & MAC 703 & 26 & $4.6-33.9$ & $(-71)-(35.2)$ & 33.7 & 28-(39.2) & (17.8)-(47.8) \\
\hline & SSB 01 & 23.1 & $18.8-26.4$ & $(9.7)-29$ & 34 & 26.9-(40.7) & $(14)-(51)$ \\
\hline & CCMP 421 & 22.6 & $17-27.6$ & (6.3)-(36.8) & 32.5 & 27.8-(37.2) & $(19.9)-(45.1)$ \\
\hline & MAC HIAp & 23 & $19.1-28.8$ & (10.7)-(36.8) & 33.5 & 25.6-(41.1) & (11.4)-(53) \\
\hline & 1046 & 20.3 & 20.0-27.9 & $(-0.4)-(40.4)$ & 33.6 & $27.2-(40.7)$ & $(15.5)-(51.8)$ \\
\hline & CCMP 2556 & 20.8 & $13.3-28.1$ & $(10.6)-(40.2)$ & 27.5 & $22.2-32.7$ & (13)-(41.1) \\
\hline & SSA 01 & 21.9 & $18-32.8$ & $(-81)-(35)$ & 34 & $25-(43.4)$ & (8.5)-(58) \\
\hline
\end{tabular}

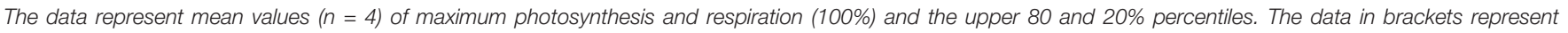
temperature calculations that exceed the measured temperature.

Trench, 1994; Anthony and Hoegh-Guldberg, 2003; Roth, 2014). The applied light conditions under which the cultures were grown are comparable to the shady in vivo conditions inside the coral tissue (Anthony et al., 2005). Furthermore, Symbiodiniaceae maximize light absorption and utilization under low light conditions by increasing the concentration of photosynthetic pigments thereby improving photosynthetic efficiency (Anthony and Hoegh-Guldberg, 2003).

The photosynthetic optimum under the prevailing environmental conditions is represented by the maximum rate of photosynthesis $\left(\mathrm{NPP}_{\max }\right)$ (Raven and Geider, 2003). The Symbiodiniaceae cultures investigated in this study revealed different type-specific eco-physiological response patterns regarding $\mathrm{NPP}_{\max }$ and respiration. These patterns are mainly caused by type-specific traits rather than as a result of the stable cultivation conditions. The data displayed a similar $\mathrm{NPP}_{\max }$ for various genera (MAC 703, CCMP 2556, and CCMP 421), which was distinct to both genotypes of Breviolum psygmophilum MAC HIAp and 1046. Furthermore, the $\mathrm{NPP}_{\max }$ of Symbiodinium linucheae SSA 01 was much lower in contrast to the other eight strains. This strain is also considered "heat tolerant" (Swain et al., 2017; LaJeunesse et al., 2018; Gegner et al., 2019) but might not be so beneficial for the coral host (Stat et al., 2008; Herrera et al., 2020). Although only minor photoinhibition was detected in the studied strains we cannot completely exclude an experimental effect as longer exposure to high irradiances could have resulted in a stronger photoinhibitory response. The data from this study, clearly indicate that SSA 01 has a much lower photosynthetic rate compared to the other strains than, for example, strain B. psygmophilum (1046), which had the highest average photosynthetic rates per chlorophyll $a$. Therefore, SSA 01 likely transfers less important photosynthetically fixed organic carbon to the host (Stat et al., 2008). The photosynthetic rates of the present study are in agreement with data of Grégoire et al. (2017), who used two identical genotypes for their experiments. The photosynthesis performance between the species were different under the same cultivation conditions (Iglesias-Prieto and Trench, 1994), pointing to genotypic traits. Previous studies indicate an important role of the genetic identity of Symbiodiniaceae strains as well as their respective eco-physiological capabilities in acclimation and adaptation to thermal stress in the reef environment (Baker, 2003; Abrego et al., 2008; Frade et al., 2008a,b). Both the endosymbiont and the host are affected by elevated temperatures. Host genetics have been identified as an important trait in the response of the symbionts (Cunning et al., 2015; Howells et al., 2016). In order to determine how the genetic identity of the symbiont is affected by elevated temperatures, the cultures were exposed to different thermal stress scenarios.

The results of this study indicated a clear species-specific threshold of upper temperature tolerance, in the range of $30^{\circ}-$ $40^{\circ} \mathrm{C}$ for all tested species, and the Symbiodiniaceae cultures demonstrated the strongest stress response with a reduced or an inhibition of photosynthesis and strongly increased respiration rate. At $35^{\circ} \mathrm{C}$, only five of nine species showed a reduced but measurable photosynthesis (Figure 4). Above $35^{\circ} \mathrm{C}$, none of the 
strains exhibited any photosynthetic activity. It can be assumed that the Symbiodiniaceae were not dead due to the continuing respiratory activity. Moreover, the results of the Symbiodiniaceae cultures showed clearly a tolerance to short-term cold stress at $10^{\circ} \mathrm{C}$ and the most efficient photosynthesis performance was measured on average at $25^{\circ} \mathrm{C}$ (Figure 4). The different Symbiodiniaceae species are classified based on a variation in thermal tolerances, which is also reflected in the results of this study (Robison and Warner, 2006; Suggett et al., 2008; DíazAlmeyda et al., 2017; Bellantuono et al., 2019). While any oxygen production at $35^{\circ} \mathrm{C}$ was not traceable in the isolates SSB 01, CCMP 2556, SSA 01, and CCMP 421, the other strains still showed a reduced activity. Durusdinium trenchii is described as heat tolerant species (Bellantuono et al., 2019) but demonstrated in culture a similar pattern as the other tested isolates up to $34^{\circ} \mathrm{C}$. The hypothesis that $D$. trenchii is more heat tolerant than the other tested strains could not be confirmed in this experiment. Thus, all tested Symbiodiniaceae exhibited quite similar temperature tolerance with an optimal photosynthetic performance between $20^{\circ}$ and $26^{\circ} \mathrm{C}$. In addition, the strains MAC 703 and SSA 01 showed an "optimal" photosynthetic capacity up to $32^{\circ} \mathrm{C}$. The upper temperature tolerance for photosynthesis of the investigated strains was between 34 and $35^{\circ} \mathrm{C}$, that of respiration even higher. Consequently, it is reasonable to assume that the increased consumption of oxygen under elevated temperatures might favor anoxic conditions within the holobiont, which can cause symbiont loss and bleaching. The results of the present study are comparable to those of other studies, which demonstrated a decrease in the maximum quantum yield of PSII and the rate of gross photosynthesis under heat stress in different zooxanthellae in culture. Impairment of photosynthesis was mainly measured at $32-34^{\circ} \mathrm{C}$ in cultivated zooxanthellae (Iglesias-Prieto et al., 1992; Warner et al., 1996; Iglesias-Prieto and Trench, 1997; Jones et al., 1998; Brown et al., 1999). In Symbiodinium microadriaticum, gradual inhibition of photosynthesis occurred at temperatures above $30^{\circ} \mathrm{C}$, followed by complete inhibition at higher temperatures of $34-36^{\circ} \mathrm{C}$ (IglesiasPrieto et al., 1992). The reason why so many zooxanthellae exhibit a similar upper temperature tolerance for photosynthesis might be related to the fact that dinoflagellates have a Type II Rubisco, which differs in many properties including heat sensitivity from Type I, the dominant form in other algal groups (Tabita et al., 2008).

In the second temperature experiment, it became clear that Breviolum minutum SSB 01 was much more susceptible to enhanced temperatures starting at $30^{\circ} \mathrm{C}$. This demonstrates different temperature thresholds between strains of B. minutum, also within the genus Breviolum the species-specific tolerances differ. This is in line with another study, where closely related Breviolum species revealed significant functional variation against elevated temperature (Bayliss et al., 2019; Herrera et al., 2020). The different genotypes exhibited decreasing photosynthetic activity at elevated temperatures, which could be an important feature for the strength of the relationship between the symbiont and the host. Some studies concluded that thermotolerance is not species- or clade-specific but is widespread and diverse among members of the genus Symbiodinium (Suggett et al., 2008; Díaz-Almeyda et al., 2017). Considering the photosynthetic machinery of coral symbionts as very sensitive to changes in the environment, it was observed that exposure of Symbiodiniaceae to light and temperature caused an impairment of the photosynthetic apparatus by PSII photoinhibition (IglesiasPrieto et al., 1992). The level of photoinhibition is partly determined by elevated temperatures or light, as these factors can accelerate PSII photodamage and inhibit repair processes (Brown et al., 1999; Takahashi et al., 2009). But other studies report that the temperature-induced inhibition of the dark reactions (Calvincycle) in zooxanthellae does not exclusively contribute to coral bleaching, while the concomitant ROS formation could be the main trigger (Hill et al., 2014).

The results of Mansour et al. (2018) found intra- and interspecific differences in the melting points of thylakoid membranes of Symbiodiniaceae species. Such process could explain the inhibition of photosynthetic oxygen production under elevated temperatures during the experiments. A still ongoing respiration was measured at higher temperatures, indicating that the repair mechanisms are working and that the experimental cooling time was too short to be used as proxy for recovery. However, in the experiment $20-34^{\circ} \mathrm{C}$ the thermal capacity of the photosynthetic membrane was probably not exceeded and hence significant differences between the strain-specific response patterns could be measured. A certain, genetically determined temperature threshold must be reached to harm the photosynthetic activity. The loss of photosynthetic function at extremely high temperatures occurs in a short time period in isolated Symbiodiniaceae cultures. The results of this study clearly indicated that the physiological properties of Symbiodiniaceae at elevated temperatures vary even within the same taxon, i.e., genotypic differentiation even on taxonomically lower rank levels plays a key role for temperature acclimation/adaptation, with consequences for the endosymbiont-host interactions (Bayliss et al., 2019). However, the physiological temperature response patterns of Symbiodiniaceae might differ between culture conditions and in symbiosis as documented for D. trenchii (Bellantuono et al., 2019). These authors compared in hospite and free-living transcriptomes, and reported strong alteration of transcriptional activity in hospite under increased temperature conditions, indicating that symbiotic interactions elicited an exacerbated stress response compared to free-living cells.

Although mainly vegetative (clonal) reproduction occurs within the Symbiodiniaceae, mutation rates can be high, resulting in new variants of individual genotypes. These genetic variations are further increased or maintained by transposons, retrotransposons, tandem repeats, or recombination during sexual reproduction (Shoguchi et al., 2013). Even hosts harboring only a single symbiont genotype can quickly accumulate genetic variation due to this high mutation rate in Symbiodiniaceae (van Oppen et al., 2011). Natural selection is likely to lead to a higher temperature tolerance in the symbiont population, since many temperature tolerance traits are inherited (Császár et al., 2010; Quigley et al., 2016). This selection in the symbiont population also strengthens the holobiont, allowing the host to survive periods of warming (Chakravarti and Van Oppen, 2018). 
Nevertheless, previous work suggests that the physiology of symbionts actually differs in culture and host (Ralph et al., 2001; Bhagooli and Hidaka, 2003; Howells et al., 2012; Chakravarti et al., 2017; Ravelo and Conaco, 2018).

Intact relationships between host and symbionts are essential for the ecological health of coral reefs, as they represent one of the most important ecosystems in tropical marine waters. Coral reefs provide many ecosystem services such as high biodiversity and productivity, habitat, fishery, water quality and biogeochemical cycling, and coastal protection (Moberg and Folke, 1999), which are negatively influenced by anthropogenic global warming.

\section{CONCLUSION}

In this study we demonstrate a necessity for a comprehensive comparative eco-physiological analysis at intra-specific taxonomic level to fully understand the underlying genetic traits responsible for the variation in thermotolerance. The results clearly demonstrate that there are significant eco-physiological differences among the tested species but also within a species, regarding light affinity and temperature tolerance. Although the short-term responses shown here do not necessarily reflect the long-term response of corals in the reef, this study highlights that symbionts play an important role in the response of holobionts to temperature increases within their average summer maxima. The results showed clearly that B. minutum (SSB 01) is much more sensitive to heat in comparison to the strain $B$. minutum (MAC 703) and to the species S. linucheae (SSA 01). Furthermore, S. linucheae (SSA 01) exhibited a lower photosynthetic rate, suggesting that this strain in symbiosis probably transfers less photosynthetically fixed organic carbon to the host (Stat et al., 2008). Therefore, future studies in which specific symbiont genotypes are introduced into the same host (e.g., Starzak et al., 2014; Hoadley et al., 2015; Herrera et al., 2020) are required to determine the role of host and symbiont in the response patterns. The different response patterns suggest that in symbiosis with a host, the carbon supply from the symbiont to the host might be affected by light and temperature. Presumably, thermal stress leads to an unbalanced bi-directional flow of metabolites between

\section{REFERENCES}

Abrego, D., Ulstrup, K. E., Willis, B. L., and Van Oppen, M. J. H. (2008). Speciesspecific interactions between algal endosymbionts and coral hosts define their bleaching response to heat and light stress. Proc. R. Soc. B Biol. Sci. 275, 2273-2282. doi: 10.1098/rspb.2008.0180

Anthony, K. R. N., and Hoegh-Guldberg, O. (2003). Kinetics of photoacclimation in corals. Oecologia 134, 23-31. doi: 10.1007/s00442-002-1095-1

Anthony, K. R. N., Hoogenboom, M. O., and Connolly, S. R. (2005). Adaptive variation in coral geometry and the optimization of internal colony light climates. Funct. Ecol. 19, 17-26. doi: 10.1111/j.0269-8463.2005.00925.x

Anthony, K. R. N., Hoogenboom, M. O., Maynard, J. A., Grottoli, A. G., and Middlebrook, R. (2009). Energetics approach to predicting mortality risk from environmental stress: A case study of coral bleaching. Funct. Ecol. 23, 539-550. doi: 10.1111/j.1365-2435.2008.01531.x

Baird, A. H., Bhagooli, R., Ralph, P. J., and Takahashi, S. (2009). Coral bleaching: the role of the host. Trends Ecol. Evol. 24, 16-20. doi: 10.1016/j.tree.2008.09.005 host and endosymbiont which should be further investigated in future studies.

\section{DATA AVAILABILITY STATEMENT}

The original contributions presented in the study are included in the article/Supplementary Materials, further inquiries can be directed to the corresponding author/s.

\section{AUTHOR CONTRIBUTIONS}

VR and UK planned and designed the ecophysiological experiments. VR conducted the ecophysiological characterization of the algal strains, and processed the data. MR-L and VR planned molecular analysis, which was conducted by VR. VR wrote the first draft of the manuscript, which was edited by MR-L and UK. All authors edited and approved the final version of this manuscript.

\section{FUNDING}

This work was supported by the DAAD Promos Fellowship to VR.

\section{ACKNOWLEDGMENTS}

We are thankful for laboratory support of photosynthesis measurements by Lara Prelle and Angelika Graiff, as well as to Juliane Müller for helping with the culture work. This Master project was funded in the frame of the DAAD Promos scheme.

\section{SUPPLEMENTARY MATERIAL}

The Supplementary Material for this article can be found online at: https://www.frontiersin.org/articles/10.3389/fmars. 2021.657348/full\#supplementary-material

Baker, A. C. (2001). Reef corals bleach to survive change. Nature 411, 765-766. doi: $10.1038 / 35081151$

Baker, A. C. (2003). Flexibility and Specificity in Coral-Algal Symbiosis: Diversity, Ecology, and Biogeography of Symbiodinium. Annu. Rev. Ecol. Evol. Syst. 34, 661-689. doi: 10.1146/annurev.ecolsys.34.011802.132417

Bayliss, S. L. J., Scott, Z. R., Coffroth, M. A., and terHorst, C. P. (2019). Genetic variation in Breviolum antillogorgium, a coral reef symbiont, in response to temperature and nutrients. Ecol. Evol. 9, 2803-2813. doi: 10.1002/ece3.4959

Bellantuono, A. J., Dougan, K. E., Granados-Cifuentes, C., and RodriguezLanetty, M. (2019). Free-living and symbiotic lifestyles of a thermotolerant coral endosymbiont display profoundly distinct transcriptomes under both stable and heat stress conditions. Mol. Ecol. 28, 5265-5281. doi: 10.1111/mec. 15300

Berkelmans, R., and Van Oppen, M. J. H. (2006). The role of zooxanthellae in the thermal tolerance of corals: A "nugget of hope" for coral reefs in an era of climate change. Proc. R. Soc. B Biol. Sci. 273, 2305-2312. doi: 10.1098/rspb. 2006.3567 
Bhagooli, R., and Hidaka, M. (2003). Comparison of stress susceptibility of in hospite and isolated zooxanthellae among five coral species. J. Exp. Mar. Bio. Ecol. 291, 181-197. doi: 10.1016/S0022-0981(03)00121-7

Blanchard, G. F., Guarini, J.-M., Richard, P., Ph, G., and Mornet, F. (1996). Quantifying the short-term temperature effect on light-saturated photosynthesis of intertidal microphytobenthos. Mar. Ecol. Prog. Ser. 134, 309-313. doi: 10.3354/meps134309

Bonthond, G., Merselis, D. G., Dougan, K. E., Graff, T., Todd, W., Fourqurean, J. W., et al. (2018). Inter-domain microbial diversity within the coral holobiont Siderastrea siderea from two depth habitats. PeerJ 6:e4323. doi: 10.7717/peerj. 4323

Brown, B. E., Ambarsari, I., Warner, M. E., Fitt, W. K., Dunne, R. P., Gibb, S. W., et al. (1999). Diurnal changes in photochemical efficiency and xanthophyll concentrations in shallow water reef corals: Evidence for photoinhibition and photoprotection. Coral Reefs 18, 99-105. doi: 10.1007/s003380050163

Buddemeier, R. W., and Fautin, D. G. (1993). Coral Bleaching as an Adaptive Mechanism. Bioscience 43, 320-326. doi: 10.2307/1312064

Burriesci, M. S., Raab, T. K., and Pringle, J. R. (2012). Evidence that glucose is the major transferred metabolite in dinoflagellate-cnidarian symbiosis. J. Exp. Biol. 215, 3467-3477. doi: 10.1242/jeb.070946

Chakravarti, L. J., and Van Oppen, M. J. H. (2018). Experimental Evolution in Coral Photosymbionts as a Tool to Increase Thermal Tolerance. Front. Mar. Sci. 5:227. doi: 10.3389/fmars.2018.00227

Chakravarti, L. J., Beltran, V. H., and van Oppen, M. J. H. (2017). Rapid thermal adaptation in photosymbionts of reef-building corals. Glob. Chang. Biol. 23, 4675-4688. doi: 10.1111/gcb.13702

Coffroth, M. A., and Santos, S. R. (2005). Genetic diversity of symbiotic dinoflagellates in the genus Symbiodinium. Protist 156, 19-34. doi: 10.1016/j. protis.2018.06.008

Connell, J. H. (1978). Diversity in Tropical Rain Forests and Coral Reefs. Science 199, 1302-1310. doi: 10.1126/science.199.4335.1302

Correa, A. M. S., and Baker, A. C. (2011). Disaster taxa in microbially mediated metazoans: How endosymbionts and environmental catastrophes influence the adaptive capacity of reef corals. Glob. Chang. Biol. 17, 68-75. doi: 10.1111/j. 1365-2486.2010.02242.x

Császár, N. B. M., Ralph, P. J., Frankham, R., Berkelmans, R., and van Oppen, M. J. H. (2010). Estimating the Potential for Adaptation of Corals to Climate Warming. PLoS One 5:9751. doi: 10.1371/journal.pone.0009751

Cunning, R., Gillette, P., Capo, T., Galvez, K., and Baker, A. C. (2015). Growth tradeoffs associated with thermotolerant symbionts in the coral Pocillopora damicornis are lost in warmer oceans. Coral Reefs 34, 155-160. doi: 10.1007/ s00338-014-1216-4

Cunning, R., Silverstein, R. N., and Baker, A. C. (2018). Symbiont shuffling linked to differential photochemical dynamics of Symbiodinium in three Caribbean reef corals. Coral Reefs 37, 145-152. doi: 10.1007/s00338-0171640-3

Dang, K., Van, Pierangelini, M., Roberty, S., and Cardol, P. (2019). Alternative Photosynthetic Electron Transfers and Bleaching Phenotypes Upon Acute Heat Stress in Symbiodinium and Breviolum spp. (Symbiodiniaceae) in Culture. Front. Mar. Sci. 6:1-10. doi: 10.3389/fmars.2019.00656

Davies, P. S. (1984). The role of zooxanthellae in the nutritional energy requirements of Pocillopora eydouxi. Coral Reefs 2, 181-186. doi: 10.1007/ BF00263571

Davy, S. K., Allemand, D., and Weis, V. M. (2012). Cell Biology of CnidarianDinoflagellate Symbiosis. Microbiol. Mol. Biol. Rev. 76, 229-261. doi: 10.1128/ mmbr.05014- 11

Decelle, J., Carradec, Q., Pochon, X., Henry, N., Romac, S., Mahé, F., et al. (2018). Worldwide Occurrence and Activity of the Reef-Building Coral Symbiont Symbiodinium in the Open Ocean. Curr. Biol. 28, 3625.e-3633.e. doi: 10.1016/ j.cub.2018.09.024

Díaz-Almeyda, E. M., Prada, C., Ohdera, A. H., Moran, H., Civitello, D. J., Iglesias-Prieto, R., et al. (2017). Intraspecific and interspecific variation in thermotolerance and photoacclimation in Symbiodinium dinoflagellates. Proc. R. Soc. B Biol. Sci. 284:1767. doi: 10.1098/rspb.2017.1767

Eakin, C. M., Morgan, J. A., Heron, S. F., Smith, T. B., Liu, G., Alvarez-Filip, L., et al. (2010). Caribbean Corals in Crisis: Record Thermal Stress, Bleaching, and Mortality in 2005. PLoS One 5:e13969. doi: 10.1371/journal.pone.0013969
Fautin, D. G., and Buddemeier, R. W. (2004). Adaptive bleaching: a general phenomenon. Hydrobiologia 530-531, 459-467. doi: 10.1007/s10750-0042642-z

Frade, P. R., Bongaerts, P., Winkelhagen, A. J. S., Tonk, L., and Bak, R. P. M. (2008a). In situ photobiology of corals over large depth ranges: A multivariate analysis on the roles of environment, host, and algal symbiont. Limnol. Oceanogr. 53, 2711-2723. doi: 10.4319/lo.2008.53.6.2711

Frade, P. R., Englebert, N., Faria, J., Visser, P. M., and Bak, R. P. M. (2008b). Distribution and photobiology of Symbiodinium types in different light environments for three colour morphs of the coral Madracis pharensis: Is there more to it than total irradiance? Coral Reefs 27, 913-925. doi: 10.1007/s00338008-0406-3

Gabay, Y., Weis, V. M., and Davy, S. K. (2018). Symbiont Identity Influences Patterns of Symbiosis Establishment, Host Growth, and Asexual Reproduction in a Model Cnidarian-Dinoflagellate Symbiosis. Biol. Bull. 234, 1-10. doi: 10. $1086 / 696365$

Gegner, H. M., Rädecker, N., Ochsenkühn, M., Barreto, M. M., Ziegler, M., Reichert, J., et al. (2019). High levels of floridoside at high salinity link osmoadaptation with bleaching susceptibility in the cnidarian-algal endosymbiosis. Biol. Open 8:45591. doi: 10.1242/bio.045591

Glynn, P. W. (1993). Coral reef bleaching: ecological perspectives. Coral Reefs 12, 1-17. doi: 10.1007/BF00303779

Glynn, P. W., and D'Croz, L. (1990). Experimental evidence for high temperature stress as the cause of El Niño-coincident coral mortality. Coral Reefs 8, 181-191. doi: 10.1007/BF00265009

Granados-Cifuentes, C., Neigel, J., Leberg, P., and Rodriguez-Lanetty, M. (2015). Genetic diversity of free-living Symbiodinium in the Caribbean: the importance of habitats and seasons. Coral Reefs 34, 927-939. doi: 10.1007/s00338-0151291-1

Grégoire, V., Schmacka, F., Coffroth, M. A., and Karsten, U. (2017). Photophysiological and thermal tolerance of various genotypes of the coral endosymbiont Symbiodinium sp. (Dinophyceae). J. Appl. Phycol. 29, 1893 1905. doi: 10.1007/s10811-017-1127-1

Helcom (1988). Declaration on the protection of the marine environment of the baltic sea. Helsinki: HELCOM.

Hennige, S. J., Smith, D. J., Walsh, S. M. S. J., McGinley, M. P., Warner, M. E., Suggett, D. J., et al. (2019). Free-living and symbiotic lifestyles of a thermotolerant coral endosymbiont display profoundly distinct transcriptomes under both stable and heat stress conditions. Ecol. Modell. 163, 1-15. doi: 10.1007/978-94-007-0114-4

Hennige, S. J., Suggett, D. J., Warner, M. E., McDougall, K. E., and Smith, D. J. (2009). Photobiology of Symbiodinium revisited: Bio-physical and bio-optical signatures. Coral Reefs 28, 179-195. doi: 10.1007/s00338-008-0444-x

Herrera, M., Klein, S. G., Campana, S., Chen, J. E., Prasanna, A., Duarte, C. M., et al. (2020). Temperature transcends partner specificity in the symbiosis establishment of a cnidarian. ISME J. 15:768-y. doi: 10.1038/s41396-02000768-y

Hill, R., Szabó, M., Rehman, A., Vass, I., Ralph, P. J., and Larkum, A. W. D. (2014). Inhibition of photosynthetic $\mathrm{CO}_{2}$ fixation in the coral Pocillopora damicornis and its relationship to thermal bleaching. J. Exp. Biol. 217, 2150-2162. doi: 10.1242/jeb. 100578

Hoadley, K. D., Pettay, D. T., Grottoli, A. G., Cai, W. J., Melman, T. F., Schoepf, V., et al. (2015). Physiological response to elevated temperature and pCO2 varies across four Pacific coral species: Understanding the unique host+symbiont response. Sci. Rep. 5, 1-15. doi: 10.1038/srep18371

Hoegh-Guldberg, O. (1999). Climate change, coral bleaching and the future of the world's coral reefs. Mar. Freshw. Res. 50, 839-866. doi: 10.1071/MF99078

Hoegh-Guldberg, O., Mumby, P. J., Hooten, A. J., Steneck, R. S., Greenfield, P., Gomez, E., et al. (2007). Coral Reefs Under Rapid Climate Change and Ocean Acidification. Science 318, 1737-1742. doi: 10.1126/science.1152509

Howells, E. J., Abrego, D., Meyer, E., Kirk, N. L., and Burt, J. A. (2016). Host adaptation and unexpected symbiont partners enable reef-building corals to tolerate extreme temperatures. Glob. Chang. Biol. 22, 2702-2714. doi: 10.1111/ gcb. 13250

Howells, E. J., Beltran, V. H., Larsen, N. W., Bay, L. K., Willis, B. L., and van Oppen, M. J. H. (2012). Coral thermal tolerance shaped by local adaptation of photosymbionts. Nat. Clim. Chang. 2, 116-120. doi: 10.1038/nclimate1330 
Hughes, D. J., Alderdice, R., Cooney, C., Kühl, M., Pernice, M., Voolstra, C. R., et al. (2020). Coral reef survival under accelerating ocean deoxygenation. Nat. Clim. Chang. 10, 296-307. doi: 10.1038/s41558-020-0737-9

Hughes, T. P., Anderson, K. D., Connolly, S. R., Heron, S. F., Kerry, J. T., Lough, J. M., et al. (2018). Spatial and temporal patterns of mass bleaching of corals in the Anthropocene. Science 359, 80-83. doi: 10.1126/science.aan8048

Hughes, T. P., Barnes, M. L., Bellwood, D. R., Cinner, J. E., Cumming, G. S., Jackson, J. B. C., et al. (2017). Coral reefs in the Anthropocene. Nature 546, 82-90. doi: 10.1038/nature22901

Hume, B. C. C., D'Angelo, C., Smith, E. G., Stevens, J. R., Burt, J., and Wiedenmann, J. (2015). Symbiodinium thermophilum sp. nov., a thermotolerant symbiotic alga prevalent in corals of the world's hottest sea, the Persian/Arabian Gulf. Sci. Rep. 5:8562. doi: 10.1038/srep08562

Iglesias-Prieto, R., and Trench, R. (1994). Acclimation and adaptation to irradiance in symbiotic dinoflagellates. I. Responses of the photosynthetic unit to changes in photon flux density. Mar. Ecol. Prog. Ser. 113, 163-175. doi: 10.3354/ meps113163

Iglesias-Prieto, R., and Trench, R. K. (1997). Acclimation and adaptation to irradiance in symbiotic dinoflagellates. II. Response of chlorophyll-protein complexes to different photon-flux densities. Mar. Biol. 130, 23-33. doi: 10. $1007 / \mathrm{s} 002270050221$

Iglesias-Prieto, R., Matta, J. L., Robins, W. A., and Trench, R. K. (1992). Photosynthetic response to elevated temperature in the symbiotic dinoflagellate Symbiodinium microadriaticum in culture. Proc. Natl. Acad. Sci. U S A. 89, 10302-10305. doi: 10.1073/pnas.89.21.10302

Jones, A., Berkelmans, R., van Oppen, M. J., Mieog, J., and Sinclair, W. (2008). A community change in the algal endosymbionts of a scleractinian coral following a natural bleaching event: field evidence of acclimatization. Proc. R. Soc. B Biol. Sci. 275, 1359-1365. doi: 10.1098/rspb.2008.0069

Jones, R. J., Hoegh-Guldberg, O., Larkum, A. W. D., and Schreiber, U. (1998). Temperature-induced bleaching of corals begins with impairment of the $\mathrm{CO} 2$ fixation mechanism in zooxanthellae. Plant Cell Environ. 21, 1219-1230. doi: 10.1046/j.1365-3040.1998.00345.x

Karim, W., Nakaema, S., and Hidaka, M. (2015). Temperature Effects on the Growth Rates and Photosynthetic Activities of Symbiodinium Cells. J. Mar. Sci. Eng. 3, 368-381. doi: 10.3390/jmse3020368

Klueter, A., Trapani, J., Archer, F. I., McIlroy, S. E., and Coffroth, M. A. (2017). Comparative growth rates of cultured marine dinoflagellates in the genus Symbiodinium and the effects of temperature and light. PLoS One 12:e187707. doi: 10.1371/journal.pone. 0187707

LaJeunesse, T. C., Parkinson, J. E., Gabrielson, P. W., Jeong, H. J., Reimer, J. D., Voolstra, C. R., et al. (2018). Systematic Revision of Symbiodiniaceae Highlights the Antiquity and Diversity of Coral Endosymbionts. Curr. Biol. 28, 2570.e2580.e. doi: 10.1016/j.cub.2018.07.008

LaJeunesse, T. C., Smith, R. T., Finney, J., and Oxenford, H. (2009). Outbreak and persistence of opportunistic symbiotic dinoflagellates during the 2005 Caribbean mass coral 'bleaching' event. Proc. R. Soc. B Biol. Sci. 276, 4139-4148. doi: $10.1098 /$ rspb.2009.1405

Lesser, M. P. (1996). Elevated temperatures in symbiotic dinoflagellates stress and inhibit photosynthesis latitudes. Limnol. Ocean. 41, 271-283.

Lesser, M. P., Bailey, M. A., Merselis, D. G., and Morrison, J. R. (2010). Physiological response of the blue mussel Mytilus edulis to differences in food and temperature in the Gulf of Maine. Comp. Biochem. Physiol. A Mol. Integr. Physiol. 156, 541-551. doi: 10.1016/j.cbpa.2010.04.012

Lewis, C., Neely, K., and Rodriguez-Lanetty, M. (2019). Recurring episodes of thermal stress shift the balance from a dominant host-specialist to a background host-generalist zooxanthella in the threatened pillar coral, Dendrogyra cylindrus. Front. Mar. Sci. 6:1-15. doi: 10.3389/fmars.2019. 00005

Mansour, J. S., Pollock, F. J., Díaz-Almeyda, E., Iglesias-Prieto, R., and Medina, M. (2018). Intra- and interspecific variation and phenotypic plasticity in thylakoid membrane properties across two Symbiodinium clades. Coral Reefs 37, 841850. doi: $10.1007 / \mathrm{s} 00338-018-1710-1$

Moberg, F., and Folke, C. (1999). Ecological goods and services of coral reef ecosystems. Ecol. Econ. 29, 215-233. doi: 10.1016/S0921-8009(99)00009-9

Muscatine, L., and Porter, J. W. (1977). Reef Corals: Mutualistic Symbioses Adapted to Nutrient-Poor Environments. Bioscience 27, 454-460. doi: 10.2307/ 1297526
Niedzwiedzki, D. M., Jiang, J., Lo, C. S., and Blankenship, R. E. (2014). Spectroscopic properties of the Chlorophyll a-Chlorophyll c 2-PeridininProtein-Complex (acpPC) from the coral symbiotic dinoflagellate Symbiodinium. Photosynth. Res. 120, 125-139. doi: 10.1007/s11120-0139794-5

Platt, T., Gallegos, C. L., and Harrison, W. (1980). Photoinhibiton of photosynthesis in natural assemblages of marine phytoplankton. J. Mar. Res. $38,687-701$.

Qin, Z., Yu, K., Chen, B., Wang, Y., Liang, J., Luo, W., et al. (2019). Diversity of Symbiodiniaceae in 15 Coral Species From the Southern South China Sea: Potential Relationship With Coral Thermal Adaptability. Front. Microbiol. 10:2343. doi: $10.3389 /$ fmicb. 2019.02343

Quigley, K. M., Willis, B. L., and Bay, L. K. (2016). Maternal effects and Symbiodinium community composition drive differential patterns in juvenile survival in the coral Acropora tenuis. R. Soc. Open Sci. 3:160471. doi: 10.1098/ rsos. 160471

Ralph, P., Gademann, R., and Larkum, A. (2001). Zooxanthellae expelled from bleached corals at $33^{\circ} \mathrm{C}$ are photosynthetically competent. Mar. Ecol. Prog. Ser. 220, 163-168. doi: 10.3354/meps220163

Ravelo, S. F., and Conaco, C. (2018). Comparison of the response of in hospite and ex hospite Symbiodinium to elevated temperature. Mar. Freshw. Behav. Physiol. 51, 93-108. doi: 10.1080/10236244.2018.1503935

Raven, J. A., and Geider, R. J. (2003). "Adaptation, Acclimation and Regulation in Algal Photosynthesis," in Photosynthesis in Algae, eds J. A. Raven, A. Larkum, S. Douglas (Berlin: Nature Publishing Group), 385-412. doi: 10.1007/978-94007-1038-2_17

Robison, J. D., and Warner, M. E. (2006). Differential impacts of photoacclimation and thermal stress on the photobiology of four different phylotypes of Symbiodinium (Pyrrhophyta). J. Phycol. 42, 568-579. doi: 10.1111/j.1529-8817. 2006.00232.x

Roth, M. S. (2014). The engine of the reef: Photobiology of the coral-algal symbiosis. Front. Microbiol. 5:1-22. doi: 10.3389/fmicb.2014.00422

Rowan, R. (2004). Thermal adaptation in reef coral symbionts. Nature 430, $742-$ 742. doi: $10.1038 / 430742$ a

Sakami, T. (2000). Effects of temperature, irradiance, salinity and inorganic nitrogen concentration on coral zooxanthellae in culture. Fish. Sci. 66, 10061013. doi: $10.1046 / j .1444-2906.2000 .00162 . x$

Sampayo, E. M., Ridgway, T., Bongaerts, P., and Hoegh-Guldberg, O. (2008). Bleaching susceptibility and mortality of corals are determined by fine-scale differences in symbiont type. Proc. Natl. Acad. Sci. U S A. 105, 10444-10449. doi: $10.1073 /$ pnas. 0708049105

Shoguchi, E., Shinzato, C., Kawashima, T., Gyoja, F., Mungpakdee, S., Koyanagi, R., et al. (2013). Draft Assembly of the Symbiodinium minutum Nuclear Genome Reveals Dinoflagellate Gene Structure. Curr. Biol. 23, 1399-1408. doi: 10.1016/ j.cub.2013.05.062

Starzak, D. E., Quinnell, R. G., Nitschke, M. R., and Davy, S. K. (2014). The influence of symbiont type on photosynthetic carbon flux in a model cnidariandinoflagellate symbiosis. Mar. Biol. 161, 711-724. doi: 10.1007/s00227-0132372-8

Stat, M., Loh, W. K. W., LaJeunesse, T. C., Hoegh-Guldberg, O., and Carter, D. A. (2009). Stability of coral-endosymbiont associations during and after a thermal stress event in the southern Great Barrier Reef. Coral Reefs 28, 709-713. doi: 10.1007/s00338-009-0509-5

Stat, M., Morris, E., and Gates, R. D. (2008). Functional diversity in coraldinoflagellate symbiosis. Proc. Natl. Acad. Sci. 105, 9256-9261. doi: 10.1073/ pnas. 0801328105

Steen, R. G., and Muscatine, L. (1984). Daily Budgets of Photosynthetically Fixed Carbon in Symbiotic Zoanthids. Biol. Bull. 167, 477-487. doi: 10.2307/1541292

Suggett, D. J., Goyen, S., Evenhuis, C., Szabó, M., Pettay, D. T., Warner, M. E., et al. (2015). Functional diversity of photobiological traits within the genus Symbiodinium appears to be governed by the interaction of cell size with cladal designation. N. Phytol. 208, 370-381. doi: 10.1111/nph.13483

Suggett, D. J., Warner, M. E., Smith, D. J., Davey, P., Hennige, S., and Baker, N. R. (2008). Photosynthesis and production of hydrogen peroxide by Symbiodinium (Pyrrhophyta) phylotypes with different thermal tolerances. J. Phycol. 44, 948956. doi: $10.1111 /$ j.1529-8817.2008.00537.x

Swain, T. D., Chandler, J., Backman, V., and Marcelino, L. (2017). Consensus thermotolerance ranking for 110 Symbiodinium phylotypes: an exemplar 
utilization of a novel iterative partial-rank aggregation tool with broad application potential. Funct. Ecol. 31, 172-183. doi: 10.1111/1365-2435.12694

Szabó, M., Larkum, A. W. D., and Vass, I. (2020). "A Review: The Role of Reactive Oxygen Species in Mass Coral Bleaching," in Photosynthesis in Algae: Biochemical and Physiological Mechanisms, eds J. A. Raven, A. Larkum, A. R. Grossman (Basingstoke: Springer Nature), 459-488. doi: 10.1007/978-3-03033397-3_17

Tabita, R. F., Satagopan, S., Hanson, T. E., Kreel, N. E., and Scott, S. S. (2008). Distinct form I, II, III, and IV Rubisco proteins from the three kingdoms of life provide clues about Rubisco evolution and structure/function relationships. J. Exp. Bot. 59, 1515-1524. doi: 10.1093/jxb/erm361

Takahashi, S., Whitney, S. M., and Badger, M. R. (2009). Different thermal sensitivity of the repair of photodamaged photosynthetic machinery in cultured Symbiodinium species. Proc. Natl. Acad. Sci. 106, 3237-3242. doi: 10.1073/pnas. 0808363106

Takahashi, S., Whitney, S., Itoh, S., Maruyama, T., and Badger, M. (2008). Heat stress causes inhibition of the de novo synthesis of antenna proteins and photobleaching in cultured Symbiodinium. Proc. Natl. Acad. Sci. 105, 42034208. doi: $10.1073 /$ pnas. 0708554105

Thornhill, D. J., LaJeunesse, T. C., Kemp, D. W., Fitt, W. K., and Schmidt, G. W. (2006). Multi-year, seasonal genotypic surveys of coral-algal symbioses reveal prevalent stability or post-bleaching reversion. Mar. Biol. 148, 711-722. doi: 10.1007/s00227-005-0114-2

Trench, R. K. (1993). Microalgal-invertebrate symbiosis: a review. Endocytobiosis Cell Res. 9, 135-175.

Van Oppen, M. J. H., and Lough, J. M. (2018). Coral Bleaching. New York City: Springer International Publishing, doi: 10.1007/978-3-319-75393-5 van Oppen, M. J. H., Bongaerts, P., Underwood, J. N., Peplow, L. M., and Cooper, T. F. (2011), The role of deep reefs in shallow reef recovery: an assessment of vertical connectivity in a brooding coral from west and east Australia. Mol. Ecol. 20, 1647-1660. doi: 10.1111/j.1365-294X.2011.05050.x

Van Oppen, M. J. H., Baker, A. C., Coffroth, M. A., and Willis, B. L. (2009). Bleaching Resistance and the Role of Algal Endosymbionts. Coral Bleaching 2009, 83-102. doi: 10.1007/978-3-540-69775-6_6

Venn, A. A., Loram, J. E., and Douglas, A. E. (2008). Photosynthetic symbioses in animals. J. Exp. Bot. 59, 1069-1080. doi: 10.1093/jxb/erm328

Warner, M. E., Fitt, W. K., and Schmidt, G. W. (1996). The effects of elevated temperature on the photosynthetic efficiency of zooxanthellae in hospite from four different species of reef coral: a novel approach. Plant Cell Environ. 19, 291-299.

Weis, V. M. (2008). Cellular mechanisms of Cnidarian bleaching: stress causes the collapse of symbiosis. J. Exp. Biol. 211, 3059-3066. doi: 10.1242/jeb. 009597

Conflict of Interest: The authors declare that the research was conducted in the absence of any commercial or financial relationships that could be construed as a potential conflict of interest.

Copyright (®) 2021 Russnak, Rodriguez-Lanetty and Karsten. This is an open-access article distributed under the terms of the Creative Commons Attribution License (CC BY). The use, distribution or reproduction in other forums is permitted, provided the original author(s) and the copyright owner(s) are credited and that the original publication in this journal is cited, in accordance with accepted academic practice. No use, distribution or reproduction is permitted which does not comply with these terms. 